Годишник Телекомуникации 2019, том 6, с. 137-145

Yearbook Telecommunications 2019, vol. 6, p. 137-145

eISSN 2534-854X

https://telecommunications.nbu.bg/bg/godishnik-telekomunikacii

DOI: https://doi.org/10.33919/YTelecomm.19.6.14

СИСТЕМА ЗА МОНИТОРИНГ И ИНТЕРНЕТ СВЬРЗАНОСТ ЗА

МАЛКИ ЗЕМЕДЕЛСКИ СТОПАНСТВА В ОТДАЛЕЧЕНИ И

ТРУДНОДОСТЬПНИ РЕГИОНИ

Георги Петров, Васил Къдрев

\title{
MONITORING AND INTERNET CONNECTIVITY SYSTEM FOR SMALL FARMS IN REMOTE AND HARD TO REACH REGIONS
}

\author{
Georgi Petrov, Vasil Kadrev
}

\begin{abstract}
Резюме: Цел на настоящата публикация е да представи съществуващите проблеми по отношение на телекомуникационната свързаност на малки и средни земеделски производители намиращи се в отдалечени и труднодостьпни планински региони. Резултатите са свързани с разработката на отворена хардуерна и софтуерна система за автоматизиран мониторинг и определяне на локалната метеорологична прогноза предназначена за използване от малки и средни земеделски производители намиращи се в отдалечени и труднодостъпни планински региони. Приноси на настоящата работа са направеният задълбочен анализ и разработените въз основа на този анализ препоръки.

Разработената система е част от проект касаещ изграждане и развитие на безплатен интернет достъп и мониторинг системи в отдалечени селски стопанства и в планинските райони на страната.
\end{abstract}

Ключови думи: автоматизирана метеорологична прогноза, малки земеделски производители, труднодостьпни райони

\begin{abstract}
The purpose of this publication is to present the existing telecommunication connectivity problems of small and medium-sized farmers located in remote and hard to reach mountainous regions. The results relate to the development of an open hardware and software system for automated monitoring and determination of local meteorological forecasts for use by small and medium-sized farmers located in remote and hard to reach mountain regions. The contributions of this work are the in-depth analysis and the recommendations developed on the basis of this analysis.

The developed system is part of a project concerning the construction and development of free internet access and monitoring systems in remote farms and in the mountainous regions of the country. Keywords: automated meteorological forecast, small farmers, hard to reach regions
\end{abstract}

\section{1. ВЬВЕДЕНИЕ}

Малките стопанства играят важна роля и значение в социално-икономическата дейност и развитие на земеделието и селските райони в България и $\mathrm{EC}$, като подпомагат устойчивото и интегрирано развитие на селските райони, водят до подкрепа доходите на домакинствата, имат съществен принос при управлението на земеделските земи, опазването на околната среда, биоразнообразието и ландшафта. Малките стопанства са тези, които поддържат живота в планинските, полупланинските и труднодостъпните райони. За целите на прилагане на политиките за подпомагане на земеделските стопанства е приетата национална дефиниция за малки стопанства, това са тези стопанства с икономически размер между 2000 до 7999 евро годишна продукция [1]. Съгласно тази дефиниция броят на малките стопанства за 2016 г. е 78 960, в сравнение за 2007 той е 119640 броя. Това показва, че броят на малките стопанства, които са регистрирани, драстично намалява през последните години, като само за справка между 2009 г. и 2018 г. общият им брой е спаднал с до $40 \%$. В планинските райони на страната развиват дейност 


\section{СИСТЕМА ЗА МОНИТОРИНГ И ИНТЕРНЕТ СВЪРЗАНОСТ ЗА МАЛКИТЕ ЗЕМЕДЕЛСКИ СТОПАНСТВА В ОТДАЛЕЧЕНИ И ТРУДНОДОСТЬПНИ РЕГИОНИ}

\section{ГЕОРГИ ПЕТРОВ, ВАСИЛ КЬДРЕВ}

22,1 хил. малки стопанства или 25,8 \% от всички. При тях също се наблюдава редукция в броя им, но в по-малки размери и темпове. Подкрепата на малките земеделски стопанства особено в планинските, полупланинските и труднодостъпните райони е важен елемент подпомагащ развитието на местните общини, културното наследство и отличителните характеристики какъвто е агротуризма, способстващ за изграждане и популяризиране на регионите. Производството на т.нар. “био”, „еко” и „планински” продукти от животински и растителен произход, както и винопроизводството придава съответната уникалност на дадения район по отношение на алтернативния геоложки и културен туризъм [2].

Нещо повече, съвременната индустрия базирана на интелектуалния фактор, както и технологиите за Интернет свързаност, позволяват на редица ангажирани в ИКТ индустрията хора да могат да работят от произволно географско място с наличен Интернет достъп. Това променя коренно възможностите за индустриално развитие на регионите, което ще наложи изграждането на лека промишленост и услуги в отдалечените райони, поради естествените процеси на миграция на финансово осигурени хора от градовете в околоградските и отдалечени райони. Към настоящия момент заетата работна сила в тези малки селски стопанства има сезонен характер, или елемент на частична заетост, но в съчетание с подобряване на локалното ресторантьорство, организирането на местно производство със запазена марка би имало само позитивен ефект при комплексната ангажираност на местното население. Трудностите, които срещат малките земеделски производители не са адекватно покрити от мерки, които държавата може и би трябвало да гарантира, което налага производителите да се консолидират на местно ниво.

Един от основните проблеми на малките производители е ниската рентабилност и често невъзможност да разширят своето производство до мащаби гарантиращи възвращаемост на инвестициите, а също така и липсата на опит и подходящо професионално образование, отсъствие на достьп до модерни технологии (цифровите услуги) и консултации, а също така липса на единна унифицирана и равноправна платформа за пласмент и доставка на продукцията. Редица от тези пречки могат да бъдат премахнати, като се тьрси консолидация на този сектор, например чрез интегрирани онлайн платформи за обмен на знания, предлагане и пласмент [3], поръчка и доставка на продукцията (от типа купи на брой), а също така и като захранващо звено на локалните хотелски вериги и селища от затворен тип. Следва да се отчита факта, че в световен мащаб потреблението на качествени земеделски продукти с гарантиран биологичен произход сериозно ще нараства, като този вид стоки ще имат непрекъснато нарастващи цени, което при правилна организация на производството и доставката им може да направи малките производители много ценени за групи частни потребители със специфични потребности и предпочитания в потреблението на чиста продукция с доказан екологично съобразен цикъл на производство. В тази връзка, по актуална информация от медиите, във Франция закупуването на продукти за ресторантите е в радиус не повече от 100 км.

Едно от условията способстващи за по-висока икономическа ефективност на малките земеделски производители е оптимизирането в потреблението на естествените природни ресурси, като слънце, вода, климатични особености и цикличност на засаждане и редуване на селскостопанската продукция, естествено наторяване и природни мерки за борба с т.нар. вредители и т.н., както и недопускане на вредни за фауната (пчели и др.) препарати. Тези мероприятия не могат да бъдат добре приложени в рамките на малките стопанства, които са отдалечени, поради отсъствието на прецизна методика за прилагане на общоприети технологии в селскостопанското производство, адаптирани към локалните специфики на климата, даденостите на почвите, дневното сльнцестоене, качество на местните водоизточници и др. Интеграцията на системите за подпомагане вземането на 
Годишник Телекомуникации 2019, том 6, с. 137-145

Yearbook Telecommunications 2019, vol. 6, p. 137-145

eISSN 2534-854X

https://telecommunications.nbu.bg/bg/godishnik-telekomunikacii

DOI: https://doi.org/10.33919/YTelecomm.19.6.14

решения базирани на предишния споделен опит между отделните стопани, а също така и научните постижения в областта на агрономията, и сравнително достьпните днес радиочестотни мониторинг станции могат да подобрят процесите свързани с мероприятия по засаждане, опазването, отглеждане и беритба на земеделската продукция. Споделеният достъп до подобни услуги ще позволи на редица малки производители да се консолидират във виртуалното пространство, което би снижило себестойността на произвежданата от тях продукция поради окрупняване на поръчките (торове, препарати, експертиза и споделяне на техника) и респективно поевтиняване на доставките (ползване на обща куриерска услуга, експресна услуга с дрон) и др.

Описаната тук отворена система за мониторинг (общо, периметров, екологичен, биологичен и др.) и приложението за изготвяне на краткосрочни локални метеорологични прогнози е развитие на по-голяма инициатива за осигуряване на свободен интернет достъп в планинските и труднодостьпни региони на страната [4]. Разработката на системата цели подсигуряване на малки обекти (къщи за гости, хижи, заслони и малки селски и горски стопанства), намиращи се извън обхвата на селищните мрежи и в зони без покритие от мобилните оператори, където инсталирането и поддръжката на сателитен или друг тип фиксиран достьп е икономически необосновано, като така се покрият т.нар. “бели петна" на картата на широколентовия достъп [5]. Описаната хардуерна система е развитие на разработка на мониторинг и система за сбор данни започната през 2017г. от инж. Боян Пресолски, студент в програма “Телекомуникации” при Нов български университет, учредител и идеолог на "Българска организация на хижите с обсервация" (ВОНО Bulgarian Observable Huts Organization". Реализираните до момента проекти са изцяло чрез проведени дарителски кампании и доказват ефективността на прилаганите решения и технология на изграждане на мрежите [6]. Това е обнадеждаващо и може да послужи, като ефективен модел за разгръщане на мрежите в планинските, полупланинските и труднодостьпните региони, в частност за нуждите на малки горски стопанства и селскостопански производители, включително следене на дребен и едър рогат добитък, “свободно” отглеждан в планините.

Ползвайки този модел на изграждане на алтернативни Интернет мрежи би позволило свързването на малки хотели, заслони и хижи с онлайн система за порьчка и доставка на зеленчуци и друга земеделска продукция от локални малки производители, като така се осигури високо качество на предлаганата храна с гарантиран биологичен произход, като драстично се снижи времето на престой на хранителните продукти преди тяхната консумация. До момента повечето туристически обекти (хижи и малки хотели) използват хранителни продукти от магазинната мрежа, което не може да допринесе за установяване и изграждане традиции в предлагането на регионални хранителни продукти и напитки, и т.н. От друга страна интегрирането на тези стопанства в единна информационна мрежа ще има и допълнителни резултати в оптимизирането на потреблението на природни ресурси, като вода за напояване, наторяване (с биологична тор), беритба (например клиентите сами да си изберат и наберат заявената от тях продукция), и засаждане според локалните климатичните условия и др. Подобна система би имала и важно екологично значение и в системите за ранна превенция от природни бедствия. Базирайки агрегирането на данни чрез локална разпределена мрежа от сензори и датчици в горските и труднодостьпни райони може да се следи както за климатичните, така и за екологичните норми, преноса на замърсители с въздушните течения, както и от валежите, следене на параметрите на планинските водосборни басейни, прогнозиране на щети нанесени от прекомерни валежи и много други фактори, като горските пожари, 


\section{СИСТЕМА ЗА МОНИТОРИНГ И ИНТЕРНЕТ СВЪРЗАНОСТ ЗА МАЛКИТЕ ЗЕМЕДЕЛСКИ СТОПАНСТВА В ОТДАЛЕЧЕНИ И ТРУДНОДОСТЫПНИ РЕГИОНИ}

\section{ГЕОРГИ ПЕТРОВ, ВАСИЛ КЪДРЕВ}

цялостно наблюдение на планинската екосистема [7]. В допълнение на това е агрегирането на данни с научно значение, такива като ниво на ултравиолетовата радиация, разпределено монтиране на сензори за детекция на космични лъчения, сеизмични датчици, в частност за мониторинг на свлачищни зони и в близост до големи язовири със земно насипни стени [8] и др. Запазвайки интерфейса на свързване отворен, и осигурявайки интелигентни модули за агрегиране на информация от различни мрежи и сензорни системи, може да се счита, че ще бъде осигурен подходящия мидълуер за мащабиране на една подобна система. Естествено на пазара съществуват вече и редица български производители (GeoSCAN, Pessl), предоставящи подобна услуга с геолокация, но тя е поскоро ориентирана към големите селскостопански производители обработващи големи обединени земеделски площи и де факто е неприложима за локално използване в планински терен. За нуждите на големите държавни производители през 80-те години на миналия век, в България има и своя сериозен опит от използването на аерокосмически методи за мониторинг [9], но отново в условията на локален климатичен феномен глобалната прогноза получавана по този начин не е особено точна (пример един дъждоносен облак може само да премине през района, без да има реално изваляване), което налага да се използват методи за локални краткотрайни метеорологични прогнози, или например определяне момента на пръскане с определени препарати така, че да има достатъчно време, за да подействат и т.н.

\section{2. ТЕХНОЛОГИИ ЗА ИНТЕРНЕТ СВЪРЗАНОСТ В ОТДАЛЕЧЕНИТЕ РАЙОНИ}

Основният проблем пред малките земеделски стопанства при въвеждането на техники за прецизно и био земеделие са свързани както с липсата на достатъчна информация, така и с отсъствието на достъп до онлайн системи за колаборация, продажба и предлагане на земеделска продукция, инструменти и услуги. Технически погледнато осигуряването на Интернет свързаност и алтернативно електрозахранване са основният фактор пречещ на въвеждането на дигиталните технологии при малките производители. В равнинните и крайселищни райони подобен достъп лесно се осигурява чрез ползването на GPRS (General Packet Radio Service - пакетна радиовръзка за общо ползване) и където е налична $3 \mathrm{G}$ мрежата на мобилните оператори, но това не важи за отдалечените области с пресечен и предимно планински терен - фиг. 1.

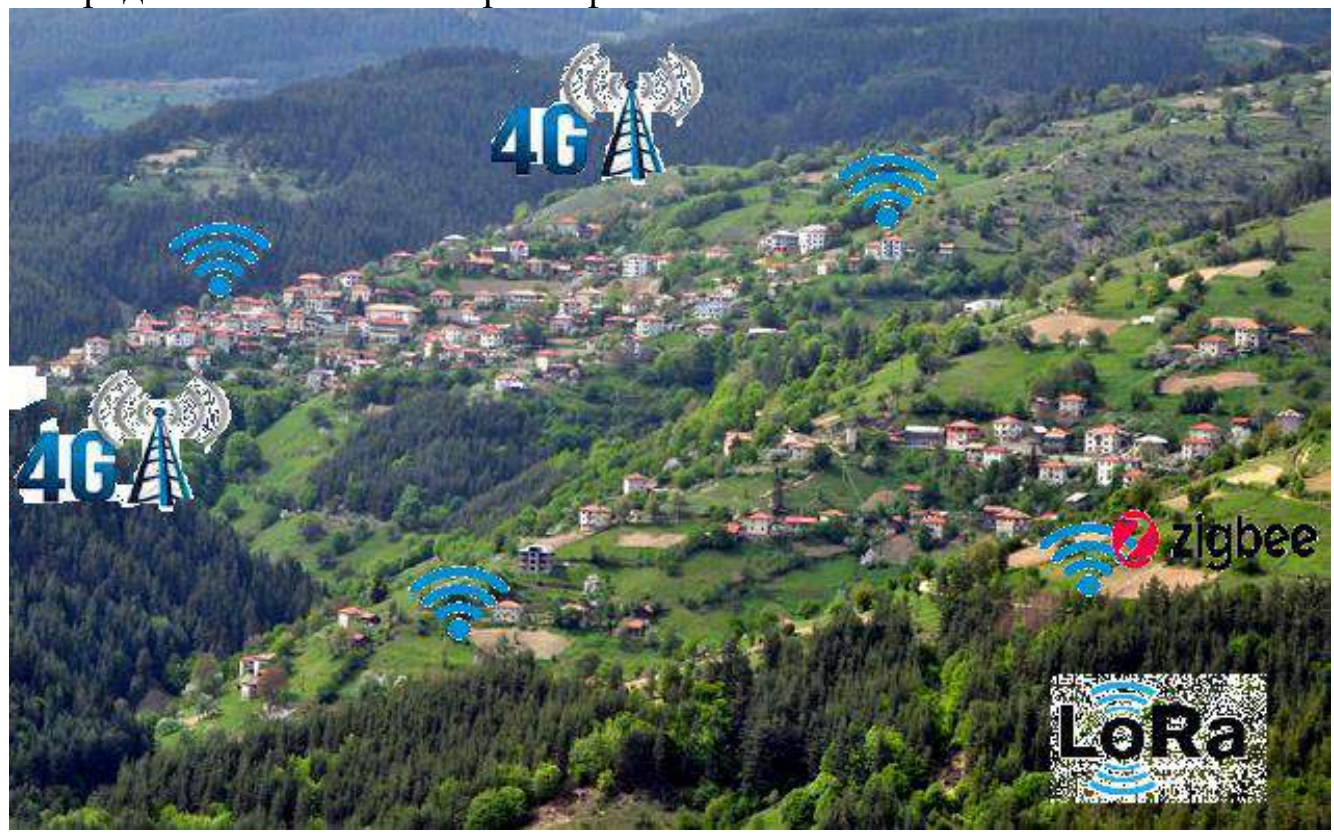

Фиг. 1. Възможности за осигуряване на технологии за Интернет свързаност в отдалечените райони. 
Годишник Телекомуникации 2019, том 6, с. 137-145

Yearbook Telecommunications 2019, vol. 6, p. 137-145

eISSN 2534-854X

https://telecommunications.nbu.bg/bg/godishnik-telekomunikacii

DOI: https://doi.org/10.33919/YTelecomm.19.6.14

Достьпьт до цифрови услуги и съдържание, а също така и до информация, днес основно става през Интернет, като за сьжаление хората живеещи в отдалечените региони рядко могат да разчитат дори на обикновена телефонна свързаност. За нуждите на поголемите производители тази услуга може да бъде предоставена чрез сателитен интернет достьп, но подобна инвестиция (с месечна такса между 50 и 150 лв. по данни от сайта на оператор Виваком към 21.10.2019г. и реална инсталационна такса на антенното и активно оборудване от не по-малко от $1000 €)$ не винаги е по силите на един или дори на няколко малки производители. Нещо повече изграждането на подобна точка за достып не решава проблема за свързаност с осигуряване на непрекъсваемо електрозахранване, което добавя допълнителен разход към цялата система, необходимо е осигуряване на соларен панел с акумулатор и инвертор, цената на подобно пълнофункционално съоръжение с къщичка за защита от климатични фактори често надвишава 2500€. Независимо от това, приложението на сателитния достьп е особено удачно за захранване на подобни отдалечени обекти, но следва да се има предвид, че качеството на услугата зависи в значителна степен от метеорологичната обстановка (мъгли, снеговалежи, дъжд). За осигуряване на необходимата цифрова пльтност на цялата територия на страната е разработен "Национален план за широколентова инфраструктура за достъп от следващо поколение" приет сPMC No 435/26.06.2014 г.

Използване на мрежите на мобилните оператори, когато те са налични, или доизграждане на инфраструктура за пакетно предаване на данни към вече изградени точки би способствало неимоверно много за подобряване зоните на покритие на мобилните оператори в планинските региони, като следва да се ползва метода на обльчване на склоновете отдолу нагоре [10]. За съжаление честотните обхвати ползвани в момента от операторите не позволяват ползване на обхвати около $400 \mathrm{MHz}$ с опция за прилагане на CDMA техники за обработка на сигнала, които честоти по-добре проникват през гъстата растителност по склоновете на планините.

Алтернатива на сателитния достып е изграждането на наземни WiFi радиорелейни мрежи от типа "точка до точка" в зоната на пряката видимост, поради ниската цена на оборудването и неговата надеждност и лекота в инсталирането и администрирането на мрежата. Практически, ако планинският склон има пряка видимост към равнината това е директно осъществимо без повторители. Проблемни са зоните, където потребителят на сигнала е в затворена котловина без налична инфраструктура в района. В тези случаи може да се използва, ако има такава налична, съществуваща кула на някой телекомуникационен оператор, но това често е сыпроводено с проблеми свьрзани със съвместното ползване на съоръжението. Тъй като става выпрос за ниски скорости на предаване на информацията за нуждите на тези стопанства, може да се приложи хибриден достъп, като от точка в зоната на пряката видимост с радиорелейната антена се разклони мрежа тип “mesh", но на по-ниски честоти. Една от тези възможности е да бъде използван $\mathrm{ZigBit}^{\mathrm{TM}}$ 700/800/900 MHz, по-ниските честоти имат свойството по-добре да проникват между гъстата растителност, но все още недостатъчно, за да осигурят линкове на поголеми разстояния и зад препятствия [11]. В тези случаи напоследьк се прилага използването на мрежи тип LoRaWan, които използват честоти $169,433,866,915 \mathrm{MHz}$ и са подходящи за изграждане на разпределена мрежа за Интернет на нещата IoT (Internet of Things). При изграждането на горски и планински мрежи остава нерешен въпросьт със осигуряването на непрекъсваемо електрозахранване на обектите. Технологиите за IоТ осигуряват дълготрайна работа с един комплект батерии, но тези данни се дават за нормални условия, стайна температура $+25 \%$, като климатичните условия в планините не 


\section{СИСТЕМА ЗА МОНИТОРИНГ И ИНТЕРНЕТ СВЪРЗАНОСТ ЗА МАЛКИТЕ ЗЕМЕДЕЛСКИ СТОПАНСТВА В ОТДАЛЕЧЕНИ И ТРУДНОДОСТЫПНИ РЕГИОНИ}

\section{ГЕОРГИ ПЕТРОВ, ВАСИЛ КЬДРЕВ}

са лесно и устойчиво определими със средногодишни отклонения в температурата +40 до -30. Това сериозно ще влоши дълготрайността на подобни мрежи и налага търсене на методи за възобновяемо захранване, от тип соларни панели. При тях съществуват същите проблеми от прекомерното загряване и охлаждане на батериите. Използване на вятьрни генератори за малки обекти не е особено удобно, тъй като въпреки наличния перманентен вятър в планините, поради ефекта на повърхностния слой на въздуха в близост до земната повърхност, не може да се осигури постоянно захранване. На помощ може да дойдат методи за пакетно радиопредаване ползвани от радиолюбителите в обхватите под $30 \mathrm{MHz}$, а именно дълговълновия (150-253 kHz), средновълновия (500-1620 kHz) и късовълновия (1620-30 $000 \mathrm{kHz}$ ), но там скоростите на предаване рядко надвишават 300 бита в секунда, нещо достатъчно за излъчване на пакетно групирана сензорна информация, като сигналът бъде предварително кодиран с код за корекция на грешките. Въпреки трудностите, навлизането на Интернет достьп по-близо до малките стопанства, макар и поетапно и чрез хибридни решения, ще допринесе неимоверно много за тяхното развитие и същевременно ще подобри параметрите на метеорологичния, геологичния и екологичния мониторинг в планинските райони с икономическо значение. Тук следва да се търсят и допълнителни начини за финансиране, например чрез агрегиране и предлагане на обработената информация на други потребители, които биха платили за нея, като туристи, научни организации работещи по проекти и т.н. Първоначално изграждането на мрежите ще става на базата на крауд фъндинг кампании, чрез спонсорство, а монтирането на оборудването може да става от студенти и ученици членуващи в съответните туристически организации и професионални обединения, например планински спасители, радиоаматьори и др.

\section{3. СЕНЗОРНИ МОДУЛИ ЗА МОНИТОРИНГ}

Въпреки че на пазара съществуват редица готови решения за мониторинг на различни метеорологични, физични, химични и оптични параметри на околната среда, подходът на който залагаме е ползването на отворен хардуер и софтуер с техники за съхранение и обработка на информацията от разпределените системи. Само по този начин може да се осигури независимост на изгражданите мрежи и системи за обработка на информацията. Централизираният подход може да бъде удобен за изграждане, но при него не могат да бъдат решени редица локални проблеми, например събирането на информация от мрежа, която няма изходяща връзка с други мрежи и т.н. Също така, предвид предназначението на системите, а именно за нуждите на малките производители, считаме за важно те сами да могат да конструират, инсталират и използват предлаганото оборудване, като на база отворения софтуер и хардуер споделят с общността своите нововъведения. Към такива проекти може да бъдат включени студенти или ученици от местни училища и т.н. Подходите ползвани при радиолюбителите могат да бъдат приложими и при малките стопани, като също така бъдат предвидени популярни мероприятия за насърчаване на тяхното членство в радиолюбителската асоциация. Пресечените и планински местности изискват употребата на неконвенционални средства за комуникация, дори и само заради избягването на вредните въздействия над технологичната и комуникационна инфраструктура в случаите на природни бедствия и обилни снеговалежи. Инициативата се стреми да осигури достъп и сертификация на поне един служител във всяко малко населено място, било то към общината или частен собственик, който да може да оперира с радиолюбителска радиостанция за нуждите на превенцията от бедствия и аварии.

В Интернет съществуват редица схеми и модули за изграждане на т.нар. Мрежи за IoT, представляващи по своята същност решения за сбор данни. Чрез употребата на малки готови електронни комплекти от типа на Arduino (https://www.arduino.cc/) и езикови нововъведения като Scratch (https://scratch.bg/), почти всеки потребител на мобилен телефон с елементарни технически познания би могъл да сглоби, свърже в мрежа и 
Годишник Телекомуникации 2019, том 6, с. 137-145

Yearbook Telecommunications 2019, vol. 6, p. 137-145

eISSN 2534-854X

https://telecommunications.nbu.bg/bg/godishnik-telekomunikacii

DOI: https://doi.org/10.33919/YTelecomm.19.6.14

стартира експлоатация на свой собствен мониторинг модул. За хората без никакви умения може да се приложи модельт на крауд фъндинг и дарителските кампании, при които група ученици изработват и даряват на даден земеделски производител миниатюрната система за мониторинг, например на времето или валежите и т.н., като в този процес се предвидят разяснителни кампании за населението. Общото тук е ползването на отворен протоколен формат за предаване и обработка на съобщенията от тези модули, като при преминаване от една в друга система се предвидят подходящите контейнери от типа XML, които се добавят към информацията на етапа на нейното финално обработване и се транспортират във външната периферия на мрежата, където скоростите на предаване са достатъчно високи. Обменът на данни между модулите в самите сензорни мрежи може да става с кратки пакети съдържащи текстова информация, ползването на двоично ориентирани протоколи не е препоръчително, тъй като поради смущения или отпадане на възли от мрежата получената информация не може ръчно да бъде възстановена. Съдържанието на пакетите не надвишава няколко десетки байта, което би ни позволило да ползваме нискоскоростни ASK модулатори с байтово ориентиран интерфейс. Запазвайки системата за предаване на информация максимално опростена, това не пречи на имплементирането на техники за кодиране на данните върху тази телеметрична платформа, като компресия и шумозащитно кодиране. Тези на пръв поглед прости устройства имат много добри параметри на работа при различни климатични условия, като количеството на повреди в тях е драстично по-ниско в сравнение с прецизните радиомодули. Следва да се има предвид и непосредствената опасност от мълнии, което е предпоставка за ползване на възможно по-проста и устойчива апаратура.

\section{4. ЗАКЛЮЧЕНИЕ}

Инициативи за осигуряване на свободен Интернет достып в планинските и труднодостьпни региони на страната, като „БОХО“, позволяват постепенното навлизане на широколентовия Интернет достьп в горските и малките селски стопанства намиращи се извън зоната на обслужване на мобилните и други комерсиални Интернет оператори. Осигуряването на свободен Интернет достъп е основно изискване за внедряването на свързани мрежово ориентирани мониторинг системи за определяне локалната метеорологична прогноза, системите за ранна превенция от бедствия (горски пожари и наводнения при проливни дъждове) и екологичен мониторинг (води, замърсяване на въздуха и почвата).

Разработеният хардуер и софтуер се отличават от други подобни проекти със своята цялостност и системен подход на проектирането и изграждането. Системата е проектирана от специалисти имащи опит в изграждането на големи системи за сбор данни, космическите съобщения и радиокомуникациите с приложения в индустрията и отговарят на най-сериозните изисквания. Имплементираните алгоритми за пренос и обработка на данните от сензорите осигуряват достоверни показатели за обикновените потребители и фермери, като стремежът е цялостното решение да е максимално опростено и лесно за поддръжка. Системата предлага няколко равнини на взаимодействие и взаимна свързаност с други хардуерни модули и софтуер и е част от голяма инициатива за осигуряване на свободен Интернет достьп в планините, при който малките горски стопанства и планински земеделски производители, както и туристи и спортисти, са поставени във фокуса на потенциалните ползватели на тези услуги и на един следващ етап ще позволи надграждане на мрежовата обвивка с услуги предоставящи добавена стойност. 


\section{СИСТЕМА ЗА МОНИТОРИНГ И ИНТЕРНЕТ СВЪРЗАНОСТ ЗА МАЛКИТЕ ЗЕМЕДЕЛСКИ СТОПАНСТВА В ОТДАЛЕЧЕНИ И ТРУДНОДОСТЬПНИ РЕГИОНИ}

\section{ГЕОРГИ ПЕТРОВ, ВАСИЛ КЪДРЕВ}

\section{5. БЛАГОДАРНОСТИ}

Настоящата публикация достига до вас благодарение на проект “Теоретични модели за развитие на дигиталното земеделие ДИАГРО”, Конкурс: Фундаментални научни изследвания - 2018 г. Финансиран от Фонд научни изследвания, конкурс „Фундаментални научни изследвания - 2018“, Договор № КП-06-Н-26/10 от 18.12.2018 г., срок на изпълнение 18.12.2018 - 18.12.2021

\section{ЛИТЕРАТУРНИ ИЗТОЧНИЦИ (REFERENCES):}

1. КОТЕВА, Нина и Минка АНАСТАСОВА-ЧОПЕВА. Роля на малките земеделски стопанства в условията на евроинтеграция. Икономика и управление на селското стопанство. 2011, (5), с. 33-43. ISSN 0205-3845.; KOTEVA, Nina i Minka ANASTASOVA-CHOPEVA. Rolya na malkite zemedelski stopanstva v usloviyata na evrointegratsiya. Ikonomika i upravlenie na selskoto stopanstvo. 2011, (5), s. 33-43. ISSN 0205-3845

2. КОСТОВА, Биляна и Ралица БЕРБЕРОВА. Геоложки феномени в Родопите-потенциал за развитие на геоложки туризъм. Екологично инженерство и опазване на околната среда. 2010, (3-4), c. 99-106. ISSN 1311-8668. ; KOSTOVA, Bilyana i Ralitsa BERBEROVA. Geolozhki fenomeni v Rodopite-potentsial za razvitie na geolozhki turizam. Ekologichno inzhenerstvo i opazvane na okolnata sreda. 2010, (3-4), s. 99-106. ISSN 1311-8668 3. KLERKX, Laurens , Emma JAKKU and Pierre LABARTHE. A review of social science on digital agriculture, smart farming and agriculture 4.0: New contributions and a future research agenda. NJAS-Wageningen Journal of Life Sciences [online]. 2019, vol. 90-91, pp. 1-16 [viewed 02 February 2020]. ISSN 1573-5214. Available from: https://doi.org/10.1016/j.njas.2019.100315

4. КОСТОВА, Десислава и Ралица БЕРБЕРОВА. Екология и геоинформационни системи (ГИС). Екологично инженерство и опазване на околната среда. 2009, (3-4), с. 102-106. ISSN 1311-8668. KOSTOVA, Desislava i Ralitsa BERBEROVA. Ekologiya i geoinformatsionni sistemi (GIS). Ekologichno inzhenerstvo i opazvane na okolnata sreda. 2009, (3-4), s. 102-106. ISSN 1311-8668

5. ДИМИТРОВ, Димитьр. Развитието на модерна съобщителна инфраструктура-предпоставка за ускорено въвеждане на високоскоростен широколентов достъп до Интернет. XXIII Международна конференция ТЕЛЕКОМ 2015, 15-16 октомври. 2015, с. 1-11. ISSN 1314-2690. DIMITROV, Dimitar. Razvitieto na moderna saobshtitelna infrastruktura-predpostavka za uskoreno vavezhdane na visokoskorosten shirokolentov dostap do Internet. XXIII Mezhdunarodna konferentsiya TELEKOM 2015, 15-16 oktomvri. 2015, s. 1-11. ISSN 1314-2690

6. ПРЕСОЛСКИ, Боян, Георги ПЕТРОВ, Филип АНДОНОВ, и Ралица БЕРБЕРОВА. Инициатива за осигуряване на свободен Интернет достъп в хижите в България. XXV Международна конференция TЕЛЕКОМ 2017, 26-27 октомври. 2017, с. 84-86. ISSN 1314-2690. PRESOLSKI, Boyan, Georgi PETROV, Filip ANDONOV, i Ralitsa BERBEROVA. Initsiativa za osiguryavane na svoboden Internet dostap v hizhite v Balgariya. HHV Mezhdunarodna konferentsiya TELEKOM 2017, 26-27 oktomvri. 2017, s. 84-86. ISSN 1314-2690

7. БЕРБЕРОВА, Ралица, Рангел ГЮРОВ и Харизан ХАРИЗАНОВ. Система за ранно оповестяване на природни бедствия. В: Сборник с доклади VI-ти международен симпозиум „Екология-устойчиво развитие“. 2006, c. 280-283. BERBEROVA, Ralitsa, Rangel GYUROV i Harizan HARIZANOV. Sistema za ranno opovestyavane na prirodni bedstviya. V: Sbornik s dokladi VI-ti mezhdunaroden simpozium „Ekologiya-ustoychivo razvitie“. 2006, s. 280-283

8. БЕРБЕРОВА Ралица и Георги ПЕТРОВ. Методи за цифрова сигнална обработка в компютьрно подпомагания анализ на радарграми от земно-насипни съоръжения. Сборник доклади от IX научна конференция с международно участие SES'2013. 2014, с. 369-376. ISSN 1313-3888. BERBEROVA Ralitsa i Georgi PETROV. Metodi za tsifrova signalna obrabotka v kompyutarno podpomaganiya analiz na radargrami ot zemno-nasipni saorazheniya. Sbornik dokladi ot IX nauchna konferentsiya s mezhdunarodno uchastie SES'2013. 2014, s. 369-376. ISSN 1313-3888

9. МИШЕВ, Д., Г. МАРДИРОСЯН, Л. ГЛОГОВ и П. СТОЯНОВ. Изисквания, проблеми и възможости на полевите мобилни комплекси за събиране на агрофизиологична информация. В: Научни трудове на Втори Национален симпозиум „Физика - селскостопанско производство “. Плевен, 1985, с. 129-134. MISHEV, D., G. MARDIROSYAN, L. GLOGOV i P. STOYANOV. Iziskvaniya, problemi i vazmozhosti na polevite mobilni kompleksi za sabirane na agrofiziologichna informatsiya. V: Nauchni trudove na Vtori Natsionalen simpozium „Fizika - selskostopansko proizvodstvo“. Pleven, 1985, s. 129-134

10. ПАСАРЕЛСКИ, Росен, Васил КЪДРЕВ и Теодора ПАСАРЕЛСКА. Петото поколение (5G)-мобилни системи и технологии за комуникации на бъдещето. ХXV Международна конференция ТЕЛЕКОМ 2017, 26 27 октомври. 2017. с. 18-26. ISSN 1314-2690. PASARELSKI, Rosen, Vasil KADREV i Teodora PASARELSKA. Petoto pokolenie (5G)-mobilni sistemi i tehnologii za komunikatsii na badeshteto. HHV Mezhdunarodna konferentsiya TELEKOM 2017, 26-27 oktomvri. 2017. s. 18-26. ISSN 1314-2690.

11. ВЪЛКОВ, Камен, Цвети ХРАНОВ и Иво ДОЧЕВ. Обзор на въздействието на електромагнитните смущения върху безжичните системи за събиране на данни, контрол и управление базирани на LORA ${ }^{\mathrm{TM}}$. ХХІІІ Международна конференция ТЕЛЕКОМ 2015, 15-16 октомври. 2015, с. 244-252. ISSN 1314-2690. 
Годишник Телекомуникации 2019, том 6, с. 137-145

\section{Yearbook Telecommunications 2019, vol. 6, p. 137-145}

eISSN 2534-854X

https://telecommunications.nbu.bg/bg/godishnik-telekomunikacii

DOI: https://doi.org/10.33919/YTelecomm.19.6.14

VALKOV, Kamen, TSveti HRANOV i Ivo DOCHEV. Obzor na vazdeystvieto na elektromagnitnite smushteniya varhu bezzhichnite sistemi za sabirane na danni, kontrol i upravlenie bazirani na LORA ${ }^{\mathrm{TM}}$. XXIII Mezhdunarodna konferentsiya TELEKOM 2015, 15-16 oktomvri. 2015, s. 244-252. ISSN 1314-2690

\section{Информация за авторите:}

доц. д-р Георги Костадинов Петров, НБУ департамент „Телекомуникации“, gpetrov@nbu.bg доц. д-р Васил Марков Къдрев, НБУ департамент „Телекомуникации“, vkadrev@nbu.bg

\section{Contacts:}

Assoc. Prof., PhD Georgi Kostadinov Petrov, NBU, Department Telecommunications, gpetrov@nbu.bg Assoc. Prof., PhD Vasil Markov Kadrev, NBU, Department Telecommunications, vkadrev@nbu.bg

Дата на постъпване на ръкописа (Date of receipt of the manuscript): 01.09.2019

Дата на приемане за публикуване (Date of adoption for publication): 27.09.2019 